\title{
Liver glucokinase gene expression is controlled by the onecut transcription factor hepatocyte nuclear factor-6
}

\author{
V.J. Lannoy ${ }^{2}$, J.F. Decaux ${ }^{3}$, C.E. Pierreux ${ }^{2}$, F.P. Lemaigre ${ }^{2}$, G.G. Rousseau ${ }^{1,2}$ \\ ${ }^{1}$ HORM Unit, Box 7529, 75 avenue Hippocrate, 1200, Brussels, Belgium \\ ${ }^{2}$ Hormone and Metabolic Research Unit, Université catholique de Louvain and Institute of Cellular Pathology, Brussels, Belgium \\ ${ }^{3}$ ICGM, CNRS-UPR 1524, Paris, France
}

\section{Diabetologia (2002) 45:1136-1141}

The third sentence of the Abstract should read as follows:

'Putative binding sites for hepatocyte nuclear factor (HNF)-6, the prototype of the ONECUT family of transcription factors, are present in the hepatic promoter of the glucokinase gene and hnf6 knockout mice are diabetic.'
Published online: 8 November 2002

(C) Springer-Verlag 2002

The online version of the original article can be found at http://dx.doi.org/10.1007/s00125-002-0856-z

Corresponding author: G. G. Rousseau, HORM Unit, Box 7529, 75 avenue Hippocrate, 1200, Brussels, Belgium, E-mail: rousseau@horm.ucl.ac.be

\section{Retraction}

\section{Letter of Withdrawal}

In the April issue of Diabetologia we published a study on gestational diabetes entitled:

'Comparison of alterations in insulin signalling pathway in adipocytes from Type 2 diabetic pregnant women with gestational diabetes mellitus' by M. Tomazic, A. Janez, A. Sketelj, A. Kocijanicic, J. Eckel, P. M. Sharma. Diabetologia (2002) 45: 502-508.

We are withdrawing the paper because not all of the authors had agreed to submit the paper for publication.

We sincerely apologise for the inconvenience. 